University of Wollongong

Research Online

Faculty of Social Sciences - Papers (Archive) Faculty of Arts, Social Sciences \& Humanities

2017

Animating geographies of making: Embodied slow scholarship for participant-researchers of maker cultures and material work

Chontel A. Carr

University of Wollongong, ccarr@uow.edu.au

Christopher R. Gibson

University of Wollongong, cgibson@uow.edu.au

Follow this and additional works at: https://ro.uow.edu.au/sspapers

Part of the Education Commons, and the Social and Behavioral Sciences Commons

Research Online is the open access institutional repository for the University of Wollongong. For further information contact the UOW Library: research-pubs@uow.edu.au 


\title{
Animating geographies of making: Embodied slow scholarship for participant- researchers of maker cultures and material work
}

\author{
Abstract \\ Accounts of making as a social and economic practice, and as a process of material transformation, are \\ accumulating both within and beyond geography. In this article, we turn our attention to how geographers \\ have engaged viscerally with the labour process of making, by putting their own bodies to work, as \\ makers themselves, or alongside those of research participants. Such embodied interventions extend \\ academic understandings of the everyday, embodied accumulation of skill and tacit knowledge, as well as \\ offering an alternative, methodologically transparent approach to nonrepresentational modes of writing. \\ We review how geographers interested in making have found ways in which to deeply engage the field, \\ often building on longstanding personal interests and auto-ethnographic methods, in the face of \\ pragmatic concerns for safety and security in the workplace, as well as the time constraints of the \\ neoliberal academy. We conclude that the flourishing slow scholarship on geographies of making has \\ opened up a productive portal through which to re-connect work and the body. Deeper insights arise from \\ implicating our labouring selves in both the making, as well as writing about making.

\section{Disciplines} \\ Education | Social and Behavioral Sciences

\section{Publication Details} \\ Carr, C. \& Gibson, C. (2017). Animating geographies of making: Embodied slow scholarship for \\ participant-researchers of maker cultures and material work. Geography Compass, 11 (6), \\ e12317-1-e12317-10.
}




\section{Animating geographies of making: embodied slow scholarship for participant- researchers of maker cultures and material work}

\section{Chantel Carr and Chris Gibson}

Accounts of making as a social and economic practice, and as a process of material transformation, are accumulating both within and beyond geography. In this article, we turn our attention to how geographers have engaged viscerally with the labour process of making, by putting their own bodies to work, as makers themselves, or alongside those of research participants. Such embodied interventions extend academic understandings of the everyday, embodied accumulation of skill and tacit knowledge, as well as offering an alternative, methodologically transparent approach to non-representational modes of writing. We review how geographers interested in making have found ways in which to deeply engage the field, often building on longstanding personal interests and auto-ethnographic methods, in the face of pragmatic concerns for safety and security in the workplace, as well as the time constraints of the neoliberal academy. We conclude that the flourishing slow scholarship on geographies of making has opened up a productive portal through which to re-connect work and the body. Deeper insights arise from implicating our labouring selves in both the making, as well as writing about making.

\section{Keywords: maker cultures; craft, labour process; embodiment; visceral; participant observation; auto-ethnography}

Full reference: Carr, C. \& Gibson, C. (2017). Animating geographies of making: Embodied slow scholarship for participant-researchers of maker cultures and material work. Geography Compass, 11 (6), e12317-1-e12317-10. 


\section{Introduction}

Making cultures are increasingly the focus of social sciences and humanities scholarship. Over several years, interest in skilful and tangible work with materials has grown substantially (see for example Adamson, 2007; Anderson, 2012; Bond, DeSilvey and Ryan 2013; Causey, 2014; Charney, 2011; Crawford, 2009; Gauntlett, 2011; Ingold, 2010, 2012, 2013; Luckman, 2013, 2015; Price 2015; Sennett, 2008; Thomas and Luckman, 2017). Geographers have made several key contributions to this burgeoning literature, embedding particular material and labour cultures in place, in ways that remind us of the deep connections between produced goods and the earthly resources from which they are made (Paton, 2013; Warren and Gibson, 2014).

Geographers have also contributed a nuanced understanding of the historical-geographical aspects of craft traditions (Thomas et al. 2013; Patchett, 2016a, 2016b; Luckman and Thomas, 2017), gendered dimensions of making within concrete spaces of work (Warren, 2016), and niche craft and manufacturing industries as they endure and adapt across particular locations over time (Gibson, 2016; Bryson and Ronayne, 2014). More recently, in light of looming ecological catastrophe, a critical geographical perspective on making has challenged romantic distinctions between 'old' traditions of craft and 'new' modes of mass manufacturing (Carr and Gibson, 2016), illuminating instead makers' manual skills, care, and dispositions with materials as survival skills for volatile futures.

In this article, we turn our attention to the embodied interventions made by geographers researching and writing about making. Our interest has been piqued by the many ways in which geographers working on making have brought their own life histories, bodies, materials and ideas to bear on fieldwork encounters, and in their writing. We are particularly interested in how geographers have put their own bodies to work alongside those of participants, or have called upon long-standing making (and re-making) pursuits outside of academia, to extend understandings of the everyday, embodied accumulation of skill and tacit knowledge. 
A decade ago Castree (2007: 857) pointed to the choice labour geographers face between handson activist-scholarship, and (more typically), 'studying labour issues without getting involved in them'. Though Castree was referring more broadly to 'the rough-and-tumble of worker politics', his observation that 'one can only change the world if one actively puts one's understanding of it to work in real situations' is central to the themes we raise here. Geographers interested in making, we suggest, have cast widely across their own histories, abilities, passions and concerns to find a point of entry into the field, in ways that enrich geographical contributions to the study of making and material work. In turn, making has opened up a productive portal within geography through which to rekindle important, yet largely under-researched connections between work and the body.

More recently, McMorran (2012) too, has observed that geographers writing about labour and work have largely tended to do so from a distance, where the predominance of the interview decouples 'the subject of study (work and the body) from its context (the workplace)'. McMorran argues that the flourishing interest in embodied experience has skirted the workplace, at the same time that labour geographies appear to have overlooked the bodies that are doing the work (see also McDowell and Court, 1994). Accordingly, McMorran (2012: 490) has called for more 'working participant observation' to fill this void, bringing work and the body back into dialogue.

Where the body and work are being brought into dialogue is in emerging non-representational writing from a cultural geographic perspective, generating questions of viscerality, hybridity, technology and nonhuman relations (Bissell and del Casino 2016; Richardson and Bissell, under review). This literature calls for nuanced unpicking of ontological ambivalences around, for instance, 'new practices of labor and the intersections of that labor with the rapidly changing 
socio-spatial relations brought about by new forms of robots, robotic futures, and automated life' (Bissell and del Casino 2016: 6). As digital technologies 'distribute the workplace' (Richardson 2017: 1) beyond a fixed location, rendering the boundaries of the workplace emergent, new theoretical perspectives are necessary to interpret resulting dislocations, ambivalences around what constitutes work, and new techno-bodily relations (Richardson 2016). The challenge of non-representational accounts is, nevertheless, to mobilise methodologically a concern for working bodies in ways that reveal relational ambivalences, while still addressing important concerns of labour geographers regarding agency, working conditions and power relations (Warren 2014). Researching bodies at work (both human and nonhuman) requires 'serious commitment to conceptual and methodological innovation' (Patchett 2016b: 1). The risk with non-representational accounts is that they remain opaque, methodologically, and to date somewhat disengaged from the communities of practice surrounding contemporary forms of work.

We propose that geographers researching and writing about making as a specific form of work have already made considerable inroads on the task of connecting work and the body, through their own embodied making practices. To explore this proposition, our paper reviews how geographers interested in making have found ways in which to deeply engage the field, pursuing auto-ethnographic and participatory research as a distinctive form of 'slow scholarship' (Mountz et al 2015) in the face of pragmatic concerns for safety and security in the workplace, as well as the constraints of the neoliberal academy. In this way, our paper offers reflection upon a series of methodological concerns around researching bodies-at-work.

There is a certain circularity at the heart of this. Researchers are interested in how bodies do work within making cultures (Patchett 2016b; Paton 2013). Yet consistently, across what are otherwise independent research projects, geographers are also increasingly drawing upon their 
own making experience, or volunteering to work alongside makers, using their own bodies to understand this work. We conclude by arguing that the flourishing scholarship of geographies of making has opened up a productive portal through which to rekindle connections between work and the body, where rich insights have developed through implicating our labouring selves in both the making, as well as researching and writing about making.

\section{Fieldwork and making}

There is a common dialogic exchange that researchers interested in making and material work would recognise, when meeting a new interview participant. Initially, some combination of bemusement and bewilderment peppers the conversation; the interviewee realises that their working body is a subject of interest, perhaps for the first time. Then, before the conversation progresses too far, an inevitable question is fired that immediately and openly engages the politics of the field, laying the groundwork for how the ensuing research will unfold:

'Do you make (weave/knit/surf/work with wood/tinker with cars/build stuff) yourself?'

For researchers of making, the politics of the field encounter are engaged immediately and openly through this question (Thomas, forthcoming). Where one encounter falls flat participant and researcher unable to reconcile a lifetime of devotion to craft and technique with the curious, yet unpractised eye of an outsider - another takes flight, borne of a shared enthusiasm for a material practice, a way of seeing the world. Our concern is how we, as researchers, engage these perspectives and come to understand the experience that underwrites them through our own encounters with making.

For researchers of making cultures keen to explore visceral practices and embodied relations with materials, there are implications for the very labour process of research itself. If working 
alongside makers proves pivotal for appreciation of the visceral relations of material work, in our experience it also invites further critical reflection on exactly what the tasks associated with academic labour processes are, and how are they organised. For labour process, understood in the Marxist sense of the division of tasks within a production process, is not limited to the mundane spaces of production, but also to creative work, including academic writing. Yet the process and practice of our fieldwork and writing remains masked by its product. As DeLyser and Hawkins (2014) argue, the polished published work obscures the means of its production, and even the production of our most frequent output (a scholarly publication) is, with few exceptions, seldom spoken of, let alone written about. Fieldwork and writing are dialogic parts of a highly managed, and increasingly corporatized and surveilled, labour process (Dowling, 2008; Dufty-Jones, 2015). Pursuing geographies of making viscerally, and thus embedding the labouring body within other labour processes, compels critical reflection on our own professional subjectivity as researchers and writers who make sense of the work of others.

Practically then, what kinds of embodied methods and research skills are needed to embrace embodied labour? McMorran (2012) advocates for working alongside to 'take seriously the spatiality and creativity of embodied work practices'. Such an approach signals a shift from ethnography, as increasingly codified in the contemporary university in terms of interview methodologies and scripts of questions approved by ethics committees, to more fluid conceptions of research encounters that involve participant observation over extended periods of time (see also Ingold, 2013, 2014; DeLyser and Sui, 2014). Geography's engagement with participant observation - particularly around questions of embodiment, labour and work - has indeed been limited (though there are notable exceptions - see for example Crang, 1994). Yet, as McMorran (2012) argues, 'working alongside' brings a different perspective on the lived experiences of work, and invites reflection on how social, material and economic relations develop and shift within the workplace over time. 
In our own research on making and material labour, this methodological engagement has required that we consciously disengage from the final 'thing' that has been produced within different cultures of making - the guitar or the cloth, the building or the work of art - shifting our critical attention to the processes, practices and skills by which it things are brought into being (Ingold 2014). This involves a commitment to doing making and material work, rather than just writing about it, with all the accompanying failed attempts and frustrations. Time is needed to think, reflect and discuss ideas with co-workers, as that work gradually unfolds. Embodied geographies of making thus require contemplation of slow scholarship strategies (cf. Mountz et al 2015), as well as the kinds of insights that only emerge gradually, through repetitive acts of doing.

In the case of making, the tasks of assembly, carving, calibrating, fixing and maintaining materials are often much more difficult than they look when we watch an expert doing them. Actually performing tasks is revealing in ways that cannot be imagined before the task is attempted. So even when work is performed in an awkward or unskilled way there are insights to be gained, perhaps even more so when clumsiness and ineptitude are foregrounded (O'Connor 2007). The varied acts in making include affective, sensory relations and skills that exist in precognitive states (Hockey and Allen-Collinson 2009), that is, prior to language and cerebral explanation. Attempts at making - even bad ones - can tell researchers something about the kinds of skills, techniques and dispositions of those who are skilled in ways academic discourse can often find difficult to capture.

A focus on labour process in both maker cultures, and in our own academic practice, traces the emergence of ideas, their conceptual and material testing and repetition, the instruments and tools with which they are brought into being. This is anything but a linear endeavour (where time 
spent gathering data in the field feeds neatly into accelerated academic outputs such as journal articles). Rather, false starts, failures and incompetencies become critical. Attending to the labour process of making offers an opportunity to think about such themes in the process of both making and writing, by following where ideas and projects go. A few of course will endure and live on in the piece that is produced. Others are consigned to the cupboard at the back of the workshop (or the file of forgotten drafts), some to be resurrected at a later date, but others to be conscribed to history as too difficult, too expensive, too complex or unclear.

\section{Geographies of making as embodied labour process}

Inspired by a legacy of work in other disciplines, most notably in anthropology and sociology (see for example Burawoy, 1998, 2001; Harper, 1987; Ingold, 2010 2012, 2013; Lave, 2011; Marchand, 2008, 2010), geographers interested in making have approached the field as embodied labour process arguably more so than is the case in labour geography generally. Labour geographies have often been dominated by the big stories, the epic struggles that occupy workers' minds, most often while their hands are occupied by manual tasks. But the small stories that summon everyday experiences and frustrations are no less important in answering questions about work (Lorimer 2003; Cameron 2012). The renewed interest in embodiment and the affective and emotional aspects of everyday life within cultural geography has created an opportunity to shift to a finer grain of analysis. Labour geographers attentive to the cultural and ethnographic have thus called for closer analysis of the mundane acts, bodily tasks, emotional terrain and instances of negotiation and resistance present in concrete workspaces, in the moments of labouring (Herod et al. 2007; Fisher and Botticello 2016; Warren 2016). What exactly do bodies do at work? By what tasks, what bodily movements, what social and material relations are things made/assembled/fixed/restored? As McMorran (2012: 493) argues, 'Given that work comprises a major part of most adult lives, it is imperative that geographers better understand not only where people work and what they say about their jobs, but also the 
unspoken aspects of work and workplaces that are difficult to address in interviews, surveys and other methods that are removed from the workplace context and its practices'. What does work means to people, and how they feel when they are doing it (Warren and Gibson 2014)? For the pleasures, trials and possibilities present in those manual tasks are a central part of the unfolding complexity of worker agency, identities and politics as manifest in concrete spaces of work.

A subsequent challenge has been how to do this, when access to workplaces is difficult, because of concerns with security, safety, training or ethics (McMorran 2012: 493). One approach widely cultivated amongst geographers interested in making has been to build relationships (and trust) over time, and often drawing on relations developed outside of the context of research work. Indeed, many geographers who write about making and material work do so subsequent to personal histories and experiences as makers and manual workers (DeLyser and Greenstein 2017). Such an approach is inherently messy (Valentine, 2001; Crang, 2005; Shaw, DeLyser and Crang, 2015; Thomas, forthcoming). It may require taking opportunities to engage with a workplace when they arrive, rather than in a preordained, linear fashion typical of the contemporary, neoliberal university's risk adverse research management and ethics approvals processes (Haggerty 2004). The implication is that attending to labour process and the embodied aspects of work might necessitate different temporalities and points of entry to research. Some engagements may stretch over long periods of time, against the background of other projects and tasks. Others may require researchers to work with happenstance - when an opportunity presents to visit a workshop previously deemed off-limits or to interview a pivotal participant after the designated period of 'fieldwork' has ended.

Almost certainly then, geographies of making and material work necessitate an approach that could best be conceived of as 'methodological bricolage' (de Certeau,1984; Levi-Strauss, 2004. See also Latham 2003; Yee and Bremner, 2011), that is adaptable to the dynamics of experiential, 
performative or nonrepresentational geographies of place (Vannini, 2015). Such geographies, as DeLyser and Greenstein (2015) demonstrate through their account of the extraordinary transnational circuits required to restore a 1941 Eastern European car, not only illuminate 'complex entanglements of reuse, repurposing and restoration' otherwise not immediately transparent to the outsider, but also bring to light 'sustained and profound emotional engagements' frequently absent in academic accounts.

The $\mathrm{PhD}$ presents one opportunity for embedding the researcher within an existing community of makers over a long period of time. For Laura Price (2016), this has meant an extended engagement with knitting groups in London and the North West of England, to explore themes such as craft consumption, the ways making practices work to connect people together through ethics of care, friendship and therapy, and knitting as activism. So too Joanna Mann, who's historical-geographical work on craft and Shetland lace knitting is documented alongside several interventions of her own wide-ranging making practices, including yarn bombing in Bristol (Mann 2015). Jessica Barnes drew upon her personal histories as a struggling musician and eBay trader of vintage items (as well as being the daughter of an artistic woodworker), to theorise aspirational economies of self in Columbus, Ohio's indie crafter scene (Barnes 2014). All three $\mathrm{PhD}$ projects engage methodological issues that have long been grappled with by feminist fieldworkers troubling the bounds between researcher, researched and the research context (England 1994; Katz 1994; McDowell 1992; Rose 1997). In the case of researcher-makers such as Price, Barnes and Mann, the blurred ground between insider and outsider (DeLyser 2001: 442) seems especially pertinent. The work of making is arguably enriched by the cultural-historical research undertaken as part of their academic work, while enfolding making practices into research work animates and enlivens academic contributions (see for example Mann's fabrication of a shawl made from a pattern dated 1867, and found in Southhampton archives (http://knitdiss.wordpress.com)). 
Another perspective on long-term engagement with participants can be drawn from the work of anthropologist Jean Lave, whose work with Liberian tailors traces out methodological and pedagogical connections between ethnography and apprenticeship. Lave's Apprenticeship in Critical Ethnographic Practice documents the long learning processes through which tailoring apprentices master their trade, against the background of her own shifting ethical and methodological frameworks. Lave advocates a critical and reflexive ethnographic practice - itself the product of a lengthy apprenticeship - that resonates with the recent work of several geographers. Sculptorgeographer David Paton (2013) for example, worked as an apprentice stonemason and sawman for the duration of his $\mathrm{PhD}$, producing an evocative auto-ethnographic portrait of the intertwining of bodies, materials, tools and place that constitute quarry life. Paton uses his firsthand experience of working the stone to demonstrate how sustained physical and emotive encounters with materials - building experience and skill - draw workers into deep and sensual relations with place:

...working the granite at Trenoweth... has offered an insight into what it means to make, and how relationships grow with a place through making with a material. Making is not just about the material; making becomes social and emotional from a position of individual knowledges working heterogeneously in a unified and creative sensuality.

Apprenticeship is also central to the work of historical geographer Merle Patchett (2016a, 2016b), whose work with taxidermists included periods of training alongside a skilled practitioner at the National Museum of Scotland. Patchett brings this first-hand experience together with archival work, to explore skilful embodiments in the present, but also as a way of working with the absence and incompleteness encountered in the historical record. For Nicola Thomas (forthcoming), an opportunity to dedicate a fractional commitment of her own 
academic labour time to the study of cloth-weaving is an approach that resonates with the nascent slow scholarship movement: finding ways of building research relationships over extended periods, and accommodating these in creative ways within the temporal constraints of academic life (cf. Mountz et al. 2015). For Harriet Hawkins, working within the context of art praxis and creative geographies involves working collaboratively with artists, as well as supervising a diverse cohort of practising artists through the $\mathrm{PhD}$ process. These varied experiments suggest ways of negotiating the time constraints of the neoliberal university by enfolding important conversations into the 'productive' time of 'doing research'.

\section{Geographies of making incorporating personal histories}

Not all such instances involve researchers learning to make alongside other non-academic makers as a proactive intervention in research process. In some cases, identities as makers (and remakers) are entangled in personal and professional histories that prefigure academic identities. Here, the sensibility and idiom are auto-ethnographic (Butz and Besio 2009). Dydia DeLyser, whose work has included insights drawn from her various longstanding collaborations with Paul Greenstein in neon sign, car and motorcycle restoration (see DeLyser 2001; DeLyser and Greenstein 2015), draws attention to the falsehood implicit in the idea that our academic lives and work identities are somehow distinct from the other long-held identities we occupy in places outside of work. This is certainly the case for several geographers currently working on projects around making, which draw on both personal and professional interests.

In our case, Chris has been pursuing an unpredictably sprawling project on guitar-making, timber scarcity and ecological uncertainty (see Gibson and Warren 2016), while training in instrument repair and restoration. Through struggles with tools and materials deeper, visceral appreciation has been forthcoming for the qualities, limits and affordances of wood, and its infinite genetic variability. While relatively new to instrument restoration, the current research is underpinned by 
a long history of musicianship and guitar-playing that spans the breadth of personal and professional life. Joining the project recently is John Steele, newly retired as Chris' Executive Dean (aka his boss), who has for decades pursued fine woodwork and cabinet-making. At the time of writing they are building a guitar together; Chris is learning how to sharpen the blades for hand planes, while John learns his first barre chords. Collaborative engagements in making and writing unfold over a long period of time, in the background of other roles and tasks. This coming-together of personal histories and professional life also resonates with Andrew Warren's work on surfboard manufacturing. Existing social networks and friendships provided by a lifelong connection with surfing provided the basis for snowballing recruitment methods. For Warren, building on already-existing social networks has meant more nuanced interactions, exchanges and discussions, 'including the embodied sensory entanglements and displays of emotion by participants, identified through their tone of voice, expression, movements of body language' (Warren 2012: 96).

Meanwhile for Chantel, doing a $\mathrm{PhD}$ opened up the opportunity to revisit places and pasts spent as an apprentice electrician in a large steelmaking plant in the early 1990s (see Carr 2017). The research sought to explore manual work and skill in an industrial city, within the context of growing ecological uncertainty. Acutely aware that the project would meet with resistance or indifference from the steel company, and mindful of her own working knowledge of the spaces and cultures workers would discuss, Chantel took the decision to conduct interviews with steelworkers in their homes rather than attempt a lengthy (and potentially fruitless) process of gaining access to the plant. It was here that a different project emerged, connecting the repair and maintenance cultures of the industrial workplace, with modes of living thoughtfully with materials in the household and beyond. 
Like Andrew Warren, common past experiences (in this case of the material cultures, work practices and routines of the steelworks) became a way of negotiating boundaries between researcher and participant throughout the project. The apprentice training scheme in particular, a fundamental part of the experience of working in the trades at this steel mill, was a way of connecting with participants through shared experiences of learning to labour with materials. This led to long and wide-ranging interviews, where unstructured discussions about the future of the city and its steelmaking enterprise sprang from more intimate observations about items at hand - scraps of material or salvaged items. Animated conversations on the prospects for a project in progress often developed into manual tasks - cleaning or making small repairs in situ, requiring the researcher to adapt from ethnographer to participant observer to actively working alongside participants and 'talking while working' (McMorran 2012: 491). Such encounters were enabled - and indeed enriched, by Chantel's own experiences of material work. Of wider relevance to pursuits of auto-ethnographic research, the blurry boundary between writing about and doing making and material work unsettles the increasingly codified 'disciplining and normalising institutional context' (Butz 2008: 239) of university ethics and risk assessment procedures.

Meanwhile, other researchers draw upon lifetimes spent making, fixing, restoring and repairing things, often with other makers or loved-ones, as pursuits undertaken irrespective of academic goals (DeLyser and Greenstein 2015). In such instances, the question is not so much how to gain access or credibility from the outside in, but rather, when and how to let boundaries between the personal and the academic dissolve, and as a consequence, face the prospect that personal identities and devotions become subject to peer review and critique (DeLyser and Greenstein, 2017). Such devotions ought not to be denigrated as uncritically romanticised motivations or attachments to fetishized commodities, but in fact celebrated, for the romantic commitment to 
creating, fixing and restoring physical things, so commonly found within maker cultures, is itself an important asset within the context of growing socio-ecological volatility.

\section{Conclusion}

Across varied cases and contexts, geographers have found points of entry into worlds of working with makers and materials. They share a particular ethics of research 'out' in the field, maintaining long relationships where there is an opportunity to give as well as receive (Ingold 2013). Our contention is that embracing the messiness and iterative nature of research through extended encounters in situ is one way in which to more deeply penetrate the world of work. Researching geographies of making through embodied, visceral practice encourages critical reflection on the struggles of academic labour. And, in iterative fashion, revealing more of the struggles of the academic labour process - its materialities and emotions in particular - leads to more enlivened understandings of work more generally.

This nevertheless remains challenging within the increasingly managed, neoliberalised university. Commitments to the manual work of making, and not just interviewing subjects, are dependent on the need to find ways to make slow scholarship possible - to work within and beyond the typical constraints of time and administrative concerns for documented consent, safety and security - as well as to validate the auto-ethnographic, exposing the personal to critical peerreview (cf. Butz 2008; Mountz et al 2015). As McMorran (2012: 494) rightly points out, 'Sceptics may argue that the kind of long-term study of a workplace espoused here is increasingly difficult or even impractical given sped-up publication expectations and limited time for fieldwork'. We have sought to show here how there are other ways of accessing the field. The body of work on making (and re-making) that has been discussed here demonstrates how other lives (DeLyser and Greenstein 2015, Thomas, forthcoming) and past lives (Paton 2013; Carr, 2017) can be connected with debates on slow scholarship (Mountz et al 2015), compelling scholars to think 
about their enrolment within neoliberal universities where productivity and accountability are measured in publications. First hand knowledges, though acquired in different ways, create richer field experiences. Moreover, they extend an opportunity to welcome different forms of knowledge into the academy.

We suggest there are deep connections between particular modes of working and wider questions of how one lives in the world. People who work with their hands are often passionate about their work. The idea of bringing something into being, whether from 'new' or raw materials, or through the re-appropriation and restoration of existing things, carries with it a romance (DeLyser and Greenstein, forthcoming). That romance ought not be valorised uncritically, but at the same time, through visceral immersion in the work of making (and remaking), geographers are increasingly acknowledging that such emotions are a fundamental part of everyday working lives, signalling the struggles and the pleasures of manual work (cf. Warren 2014). Extended encounters with makers and material work - 'getting one's hands dirty', as Castree (2007) puts it - enrich insights on the corporeal, affective and emotional labours and politics of work. In so doing, productive possibilities emerge to 'ground' non-representational theories of bodies-at-work (cf. Bissell and del Casino 2016) through methodologically transparent alternatives. Such alternatives in turn also shed light on the serendipitous, collaborative and contingent nature of our own 'work' of researching and writing. 


\section{References}

Adamson, G. (2007). Thinking through craft. London and New York: Bloomsbury.

Anderson, C. (2012). Makers: The new industrial revolution. New York: Crown Business.

Barnes, J. (2014) Aspirational economies of self and city: The values and governance of independent crafters in Columbus, Obio. $\mathrm{PhD}$ thesis, Ohio State University.

Bissell, D. and del Casino Jr., V. (2016) Wither labor geography and the rise of the robots? Social \& Cultural Geography. http://dx.doi.org/10.1080/14649365.2016.1273380.

Bond, S., DeSilvey, C. and Ryan, J. (2013). Visible mending: Everyday repairs in the south west. Axminster: Uniform Books.

Burawoy, M. (1998) The extended case method. Sociological Theory, 16: 4-33.

Burawoy, M. (2001) Manufacturing the global. Ethnography, 2: 147-159.

Butz, D. (2008) Sidelined by the guidelines: reflections on the limitations of standard informed consent procedures for the conduct of ethical research. ACME: An International Journal for Critical Geographies, 7: 239-259.

Butz, D. and Besio, K. (2009) Authoethnography. Geography Compass, 3: 1600-1674.

Bryson, J.R. and Ronayne, M. (2014) Manufacturing carpets and technical textiles: Routines, resources, capabilities, adaptation, innovation and the evolution of the British textile industry. Cambridge Journal of Regions, Economy and Society, 7: 471-488. 
Cameron, E. (2012) New geographies of story and storytelling. Progress in Human Geography, 36: 573-592.

Carr, C (2017) Maintenance and repair beyond the perimeter of the plant: Linking industrial labour and the home. Transactions of the Institute of British Geographers.

Carr, C. and Gibson, C. (2016) Geographies of making: rethinking materials and skills for volatile futures. Progress in Human Geography, 40: 297-315.

Castree, N. (2007) Labour geography: A work in progress. International Journal of Urban and Regional Research, 31: 853-862.

Causey, J. (2014). Brooklyn makers: Food, design, craft, and other scenes from the tactile life. San Francisco: Chronicle.

Charny, D. (2011). The power of making. London: V\&A Museum.

Crang, M. (2005) Qualitative methods: There is nothing outside the text? Progress in Human Geography, 29: 225-233.

Crang, P. (1994) It's showtime: On the workplace geographies of display in a restaurant in southeast England. Environment and Planning D: Society and Space, 12: 675-704.

Crawford, M. (2009). Shop class as soul craft: An enquiry into the value of work. New York: Penguin.

De Certeau, M. (1984). The Practice of Everyday Life. Trans. S. Rendall. Berkeley: University of California Press.

DeLyser, D. (2001) 'Do you really live here?' Thoughts on insider research. The Geographical Review, 91: 441-453 
DeLyser, D. and Greenstein, P. (2015) “Follow that car!” Mobilities of enthusiasm in a rare car's restoration. The Professional Geographer, 67: 255-268.

DeLyser, D. and Greenstein, P. (2017) The devotions of restoration: enthusiasm, materiality, and making three "Indian Motocycles" new. Annals of the Association of American Geographers.

DeLyser, D. and Hawkins, H. (2014) Introduction: writing creatively - process, practice, and product. Cultural Geographies, 21: 131-134.

DeLyser, D. and Sui, D. (2014) Crossing the qualitative-quantitative chasm III: enduring methods, open geography, participatory research, and the fourth paradigm. Progress in Human Geography, 38: 294-307.

Dowling, R. (2008). Geographies of identity: Labouring in the 'neoliberal' university. Progress in Human Geography, 32: 818-820.

Dowling, R., Lloyd, K. and Suchet-Pearson, S. (2015) Qualitative methods I: Enriching the interview. Progress in Human Geography, DOI: 10.1177/0309132515596880

Dufty-Jones, R. (2015) Making space/time for writing in the neoliberal university. https://www.uowblogs.com/ausccer/2015/10/25/making-spacetime-for-writing-in-theneoliberal-university-the-role-of-the-sabbatical// (last accessed 21 September 2016).

England, K. (1994) Getting personal: Reflexivity, positionality, and feminist research. Professional Geographer, 46: 80-89.

Fisher, T. and Botticello, J. (2016) Machine-made lace, the spaces of skilled practices and the paradoxes of contemporary craft production. cultural geographies http://journals.sagepub.com/doi/abs/10.1177/1474474016680106. 
Gabler, A. (2015) Workplace ethnographies - An underestimated source of subject-oriented work research. International Journal of Action Research, 11: 119-145.

Gauntlett, D. (2011). Making Is connecting: The social meaning of creativity, from DIY and knitting to YouTube and web 2.0. Cambridge: Polity Press.

Gibson, C. (2016) Material inheritances: how place, materiality and labor process underpin the path-dependent evolution of contemporary craft production. Economic Geography, 92: 61-86.

Gibson, C. and Warren, A. (2016) Resource-Sensitive Global Production Networks: reconfigured geographies of timber and acoustic guitar manufacturing. Economic Geography, 92: 430-454.

Haggerty, K. (2004) Ethics creep: Governing social science research in the name of ethics. Qualitative Sociology, 27: 391-414.

Harper, D. (1987). Working Knowledge: Skill and Community in a Small Shop. Chicago: University of Chicago Press.

Herod, A., Rainnie, A. and McGrath-Champ, S. (2007) Working space: Why incorporating the geographical is central to theorizing work and employment practices. Work, Employment and Society, 21: 247-264.

Hockey, J. and Allen-Collinson, J. (2009) The sensorium at work: The sensory phenomenology of the working body. Sociological Review, 57: 217-39.

Ingold, T. (2014), 'That's enough about ethnography!', HAU: Journal of Ethnographic Theory, 4: 383-395.

Ingold, T. (2010) The textility of making. Cambridge Journal of Economics, 34: 91-102. 
Ingold, T. (2012) Toward an ecology of materials. Annual Review of Anthropology, 41: 427-442.

Ingold, T. (2013). Making: Anthropology, archaeology, art and architecture. Abingdon: Routledge.

Ingold, T. (2014) That's enough about ethnography! HAU: Journal of Ethnographic Theory, 4: 383395.

Katz, C. (1994) Playing the field: Questions of fieldwork in geography. Professional Geographer, 46: $67-72$.

Latham, A. (2003) Research, performance, and doing human geography: Some reflections on the diary-photograph, diary-interview method. Environment and Planning A, 35: 1993-2017.

Lave, J. (2011). Apprenticeship in critical ethnographic practice. Chicago: University of Chicago Press.

Levi-Strauss, C. (2004). The Savage Mind. Chicago: University of Chicago Press.

Lorimer, H. (2003) Telling small stories: Spaces of knowledge and the practice of geography. Transactions of the Institute of British Geographers, 28: 197-217.

Luckman, S. (2013) The aura of the analogue in a digital age: Women's crafts, creative markets and home-based labour after Etsy. Cultural Studies Review, 19: 249-270.

Luckman, S. (2015). Craft and the creative economy. Basingstoke: Palgrave Macmillan.

Luckman, S. and Thomas, N. (eds) (2017). Craft economies: Cultural economies of the handmade. London: Bloomsbury.

Mann, J. (2015) Towards a politics of whimsy: Yarn bombing the city. Area, 47: 65-72. 
Marchand, T. (2008) Muscles, morals and mind: Craft apprenticeship and the formation of person. British Journal of Educational Studies, 56: 245-271.

Marchand, T. (2010) Making knowledge: Explorations of the indissoluble relation between minds, bodies and environment', Journal of the Royal Anthropological Institute, (N.S.): S1-S21.

McDowell, L. (1992) Feminism, feminists and research methods in human geography.

Transactions of the Institute of British Geographers, 17: 399-416.

McDowell, L. And Court, G. (1994) Performing work: bodily representations in merchant banks. Environment and Planning D: Society and Space, 12: 727-750.

McMorran, C. (2012) Practising workplace geographies: Embodied labour as method in human geography. Area, 44: 489-495.

Mountz, A., Bonds, A., Mansfield, B., Lloyd, J., Hyndman, J., Walton-Roberts, M., Basu, R., Whitson, R., Hawkins, R., Hamilton, T. and Curran, W. (2015) For slow scholarship: A feminist politics of resistance through collective action in the neoliberal university. ACME International EJournal for Critical Geographies, 14: 1235-1259.

O'Connor, E. (2007) Embodied knowledge in glassblowing: The experience of meaning and the struggle towards proficiency. The Sociological Review, 55:126-141.

Patchett, M. (2016a) The taxidermist's apprentice: Stitching together the past and present of a craft practice. Cultural Geographies, 23: 401-419.

Patchett, M. (2016b) Taxidermy workshops: Differently figuring the working of bodies and bodies at work in the past. Transactions of the Institute of British Geographers, DOI: $10.1111 / \operatorname{tran} .12171$ 
Paton, D.A. (2013) The quarry as sculpture: The place of making. Environment and Planning A, 45: 1070-1086.

Price, L. (2015) Knitting and the city. Geography Compass, 9: 81-95.

Price, L. (2016) Knitted geographies: Materials, Making, and Creativity. PhD thesis, Royal Holloway, University of London.

Richardson, L. (2016) Feminist geographies of digital work. Progress in Human Geography http://journals.sagepub.com/doi/abs/10.1177/0309132516677177

Richardson, L. (2017) Sharing as a postwork style: digital work and the co-working office. Cambridge Journal of Regions, Economy and Society. https://doi.org/10.1093/cjres/rsx002

Richardson, L. and Bissell, D. Geographies of digital skill. Geoforum. (under review).

Rose, G. (1997) Situating knowledges: Positionality, reflexivities and other tactics. Progress in Human Geography, 21: 305-320.

Sennett, R. (2008). The craftsman. New Haven: Yale University Press.

Shaw, W., DeLyser, D. and Crang, M. (2015) Limited by imagination alone: research methods in cultural geography. Cultural Geographies, 22: 211-215.

Thomas, N.J. (forthcoming) Weaving four-shaft relational geographies: genealogies, looms, livelihoods and woven textiles (under review)

Thomas N., Harvey, D.C. and Hawkins, H. (2013) Crafting the region: Creative industries and practices of regional space. Regional Studies, 47: 75-88.

Thomas, N. and Luckman, S., (eds) (2017) Craft communities: Making, social media and alternative economies of the handmade, London: Bloomsbury. 
Valentine, G. (2001) At the drawing board: Developing a research design. In Qualitative methodologies for geographies: Issues and debates, ed. M. Limb and C. Dwyer, London: Arnold, pp41-54.

Vannini. P. (2015). Non-representational methodologies: Re-envisioning research. Abingdon: Routledge.

Warren, A. (2012). Soulful work or selling the soul? Cultural production and the custom surfboard industry. PhD thesis, School of Earth and Environmental Sciences, University of Wollongong. (accessed at http://ro.uow.edu.au/theses/3486)

Warren, A. 2014. Working culture: the agency and employment experiences of nonunionized workers. Environment and Planning A 46(10):2300-2316.

Warren, A. (2016) Crafting masculinities: gender, culture and emotion at work. Gender, Place \& Culture, 32: 36-54.

Warren, A. and Gibson, C. (2014) Surfing places, surfboard-makers: Crafting, creativity and cultural heritage in Hawai'i, California and Australia. Honolulu: University of Hawai'i Press. Yee, Joyce and Bremner, Craig (2011) Methodological bricolage: What does it tell us about design? Paper presented at Doctoral Design Education Conference, 23-25 May 2011, Hong Kong Polytechnic, Hong Kong. (Accessed at nrl.northumbria.ac.uk/8822/1/313_Yee_Bremner_(2).pdf on 21 November 2016) 